\title{
Mechanical Characterization of Wood Apple Shell Powder and Tamarind Shell Powder Reinforced with Epoxy Resin
}

\author{
Nadeem Pasha $\mathrm{S}^{[1]}$, Dr. Attel Manjunath ${ }^{[2]}$, Sagar S R ${ }^{[3]}$ \\ ${ }^{[1]}$ (M. Tech Student, Department of Mechanical Engineering, Acharya Institute of Technology, Bangalore, India.) \\ ${ }^{[2]}$ (H.O.D, Department of Mechanical Engineering, Acharya Institute of Technology, Bangalore, India.) \\ ${ }^{\text {[3] }}$ (Lecturer, Department of Mechanical Engineering, Amruta Institute of Engineering \&Management Sciences - Polythenic,
} Bidadi (Bangalore), India.)

\begin{abstract}
In this work, Variation of tensile ,compression and impact test of the tamarind shell and wood shell particulate composites was studied .From experimental results, it is found that ,composites prepared with $25 \%$ of WAS and $5 \%$ TS powder reinforced epoxy composites exhibited better tensile, compression and flexural properties as compared to $0 \%+30 \%, 5 \%+25 \%, 10 \%+20 \%$, and $15 \%+15 \%$ combinations.

For impact studies all samples have exhibited the same amount of energy absorations for all combinations. This study reveals that, drop in the mechanical Properties for the 30\% WAS + 0\% TS composites and slight increment in the mechanical properties for increase in the TS percentage with the WAS.
\end{abstract}

Keywords - Epoxy Resin, Hardener, Tamarind Shell Powder, Tamarind Shell Powder

\section{INTRODUCTION}

The engineering importance of a composite material is that, two or more distinctly different materials combine to form a composite material that possesses properties that are superior to those of the individual materials. A simple example of a composite is the plywood. A plywood is a wood product out of many sheets of wood veneer, pressed together and glued. When layers like this are put together it produces a very sturdy and durable wood. Plywood is used instead of plain wood because of its resistance to cracking, shrinkage and its general high degree of strength.

\section{MATERIALS AND METHODOLOGY}

\subsection{Tamarind Shell Powder}

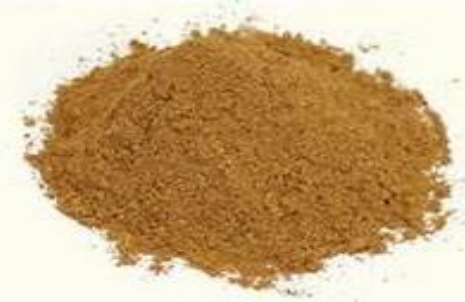

Figure 2.1.1: Tamarind shell powder

Tamarind is one of the very developed trees in India. Truth be told India is one of the most astounding cultivators of Tamarind on the planet. Tamarind comprises of 3 sections tamarind organic product mash which is palatable, hard green natural product mash, and tamarind seed. Tamarind organic product test powder commonly known as Tamarind Shell Powder (TSP).

\subsection{Wood Apple Shell Powder}

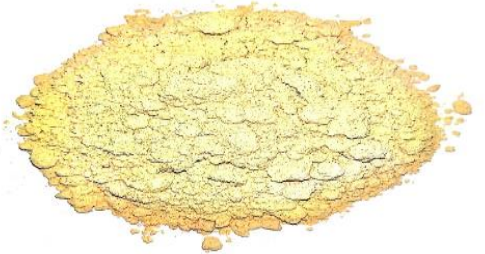

Figure 2.2.1: Wood apple shell powder

The Wood apple shell was dried in outside and granulated into powder utilizing a pummeling machine, the powder was sieved as per BS 1377:1998 standard. The compound investigation of the wood apple shell was finished with Absorption Spectrometer (AAS) Peck in rudder 2006 model. The molecule size utilized was $280 \mu \mathrm{m}$.

\subsection{Matrix system}

\subsubsection{Epoxy Resin $(L-12)$}

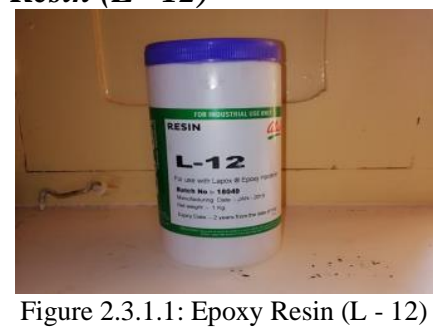

Epoxy L-12 is a fluid, unmodified epoxy sap of medium thickness which can be utilized with different hardeners for making glass fibre fortified composites.

\subsubsection{Hardener $(K-6)$}

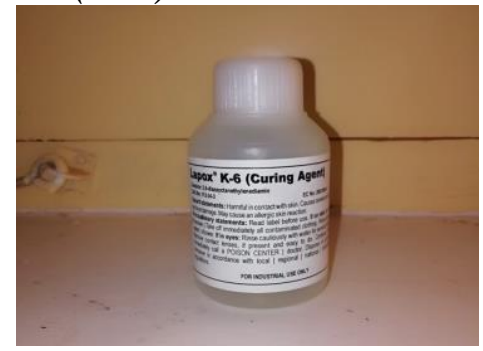

Figure 2.3.2.1: Hardener (K - 6) 
Hardener $\mathrm{K}-6$ is a low consistency room temperature restoring fluid hardener. It is normally utilized for hand layup applications. Being fairly responsive, it gives a short pot-life and fast fix at ordinary encompassing temperatures.

Table 1: Details of Constituent Properties as Supplied by

\begin{tabular}{|c|c|c|c|c|c|}
\hline \multicolumn{6}{|c|}{ Manufacturer } \\
\hline Constituent & $\begin{array}{l}\text { Trad } \\
\mathrm{e} \\
\mathrm{Nam} \\
\mathrm{e}\end{array}$ & $\begin{array}{c}\text { Chemical } \\
\text { Name }\end{array}$ & $\begin{array}{c}\text { Epoxid } \\
\mathrm{e} \\
\text { Equiva } \\
\text { lent }\end{array}$ & $\begin{array}{l}\text { Densit } \\
\mathrm{y}\end{array}$ & Supplier \\
\hline Resin & L-12 & DGEBA & $\begin{array}{l}182- \\
192\end{array}$ & 1.262 & $\begin{array}{c}\text { Yuje } \\
\text { Banglore }\end{array}$ \\
\hline Hardener & K - 8 & TETA & & 0.954 & \\
\hline
\end{tabular}

\subsection{Procedure for particulate composite Plates}

(Methodology)

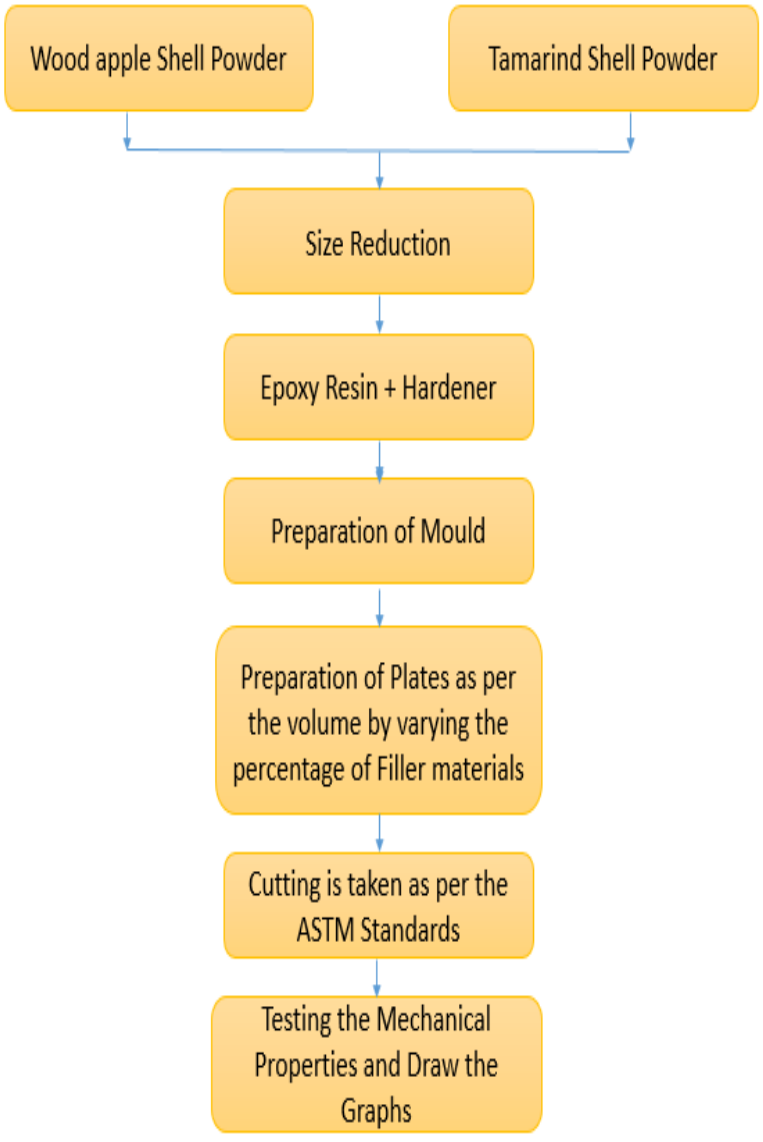

\section{SIZE OF PARTICULATE COMPOSITES}

A form of size $280 \mathrm{~mm} \mathrm{X} 150 \mathrm{~mm} \mathrm{X} \mathrm{6mm} \mathrm{was} \mathrm{set} \mathrm{up} \mathrm{of}$ hardened steel for getting ready Plate tests. Form comprises of a base plate, outline that could be destroyed to encourage simple evacuation of throwing after the restoring. Every one of the surfaces of the form were covered with wax. All the internal surfaces of shape, interacting with surfaces of composite to be cast are spread with uniform covering of wax so as to encourage the arrival of the cast piece.

Volume $=$ Length $\times$ Breadth $\times$ Height

Volume $=280 \times 150 \times 6$

Volume $=252000 \mathrm{~mm}^{2}$

$$
=252 \mathrm{~cm}^{3}
$$

Table 2: Mass Calculation

\begin{tabular}{|c|c|c|c|c|c|c|}
\hline $\begin{array}{l}\text { Sl } \\
\mathrm{N}_{0}\end{array}$ & $\begin{array}{c}\text { Percentage } \\
\text { of Wood } \\
\text { apple shell } \\
(\%)\end{array}$ & $\begin{array}{l}\text { Mass of } \\
\text { Tamarind } \\
\text { shell in } \\
\text { Grams }\end{array}$ & $\begin{array}{c}\text { Percentage } \\
\text { of Tamarind } \\
\text { shell } \\
(\%)\end{array}$ & $\begin{array}{l}\text { Mass of } \\
\text { Wood } \\
\text { apple } \\
\text { shell in } \\
\text { Grams }\end{array}$ & $\begin{array}{l}\text { Percentage of } \\
\text { Epoxy (L-12) } \\
\text { with hardener } \\
\text { (K-6) in }(\%)\end{array}$ & $\begin{array}{c}\text { Mass of } \\
\text { Epoxy in } \\
\text { Grams }\end{array}$ \\
\hline 1 & 15 & 40.36 & 15 & 19.28 & 70 & 222.26 \\
\hline 2 & 20 & 53.82 & 10 & 12.85 & 70 & 222.26 \\
\hline 3 & 25 & 67.28 & 5 & 6.43 & 70 & 222.26 \\
\hline 4 & 30 & 80.74 & 0 & 0 & 70 & 222.26 \\
\hline
\end{tabular}

4 SAMPLES PREPARATION

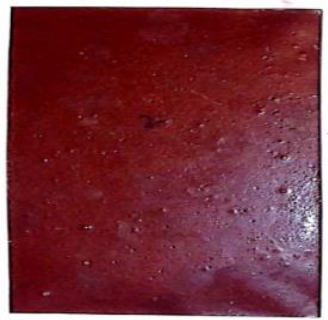

1. $15 \% \mathrm{WAS}+15 \% \mathrm{TS}$

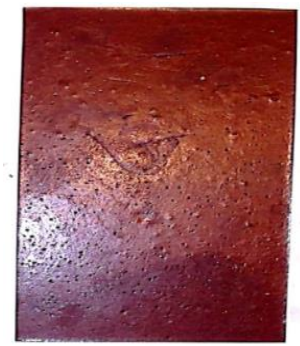

3. $25 \% \mathrm{WAS}+5 \% \mathrm{TS}$ Figure 4.1.1: Samples Preparation

Table 3: Sample coding

\begin{tabular}{|c|c|c|c|}
\hline \multirow{2}{*}{$\begin{array}{c}\text { Sl. } \\
\text { No. }\end{array}$} & \multirow{2}{*}{ Sample Code } & \multicolumn{2}{|c|}{$\begin{array}{c}\text { Combinations of fiber } \\
\text { powders }\end{array}$} \\
\cline { 3 - 4 } & & WAS & TS \\
\hline 1. & $30 \%$ WAS + 0\% TS & $30 \%$ & $0 \%$ \\
\hline 2. & $25 \%$ WAS + 5\% TS & $25 \%$ & $5 \%$ \\
\hline 3. & $20 \%$ WAS + 10\% TS & $20 \%$ & $10 \%$ \\
\hline 4. & $15 \%$ WAS + 15\% TS & $15 \%$ & $15 \%$ \\
\hline
\end{tabular}

In this study effect of variation of WAS and TS powders were carried out and the results were discussed below for tensile, compression and flexural tests.

\subsection{Tensile Test:}

\section{RESULTS AND DISCUSSIONS}

The tensile tests were conducted with respect to ASTM D3039-76 standards in a Universal Testing Machine. 


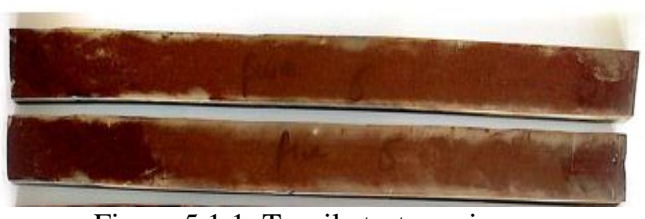

Figure 5.1.1: Tensile test specimens

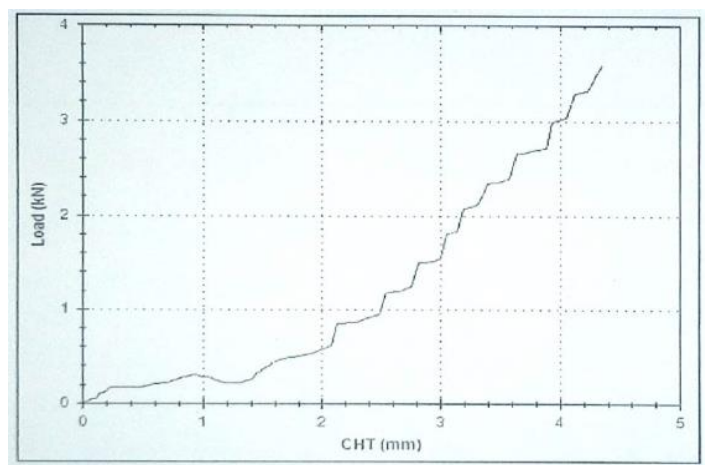

(a) sample 1

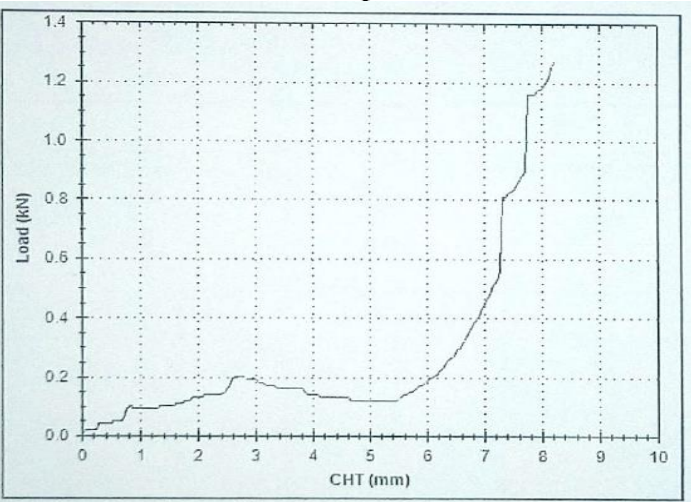

(b) sample 2

Figure 5.1.2: Load v/s displacement diagram for 30\% WAS + 0\% TS composites

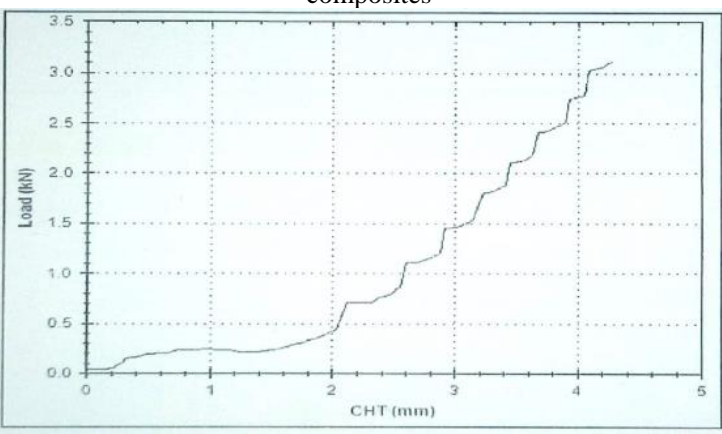

(a) sample 1

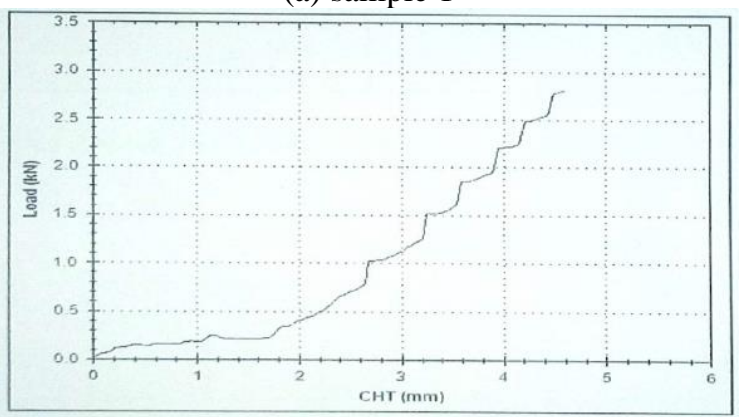

(b) sample 2

Figure 5.1.3: Load v/s displacement diagram for $25 \%$ WAS + 5\% TS composites

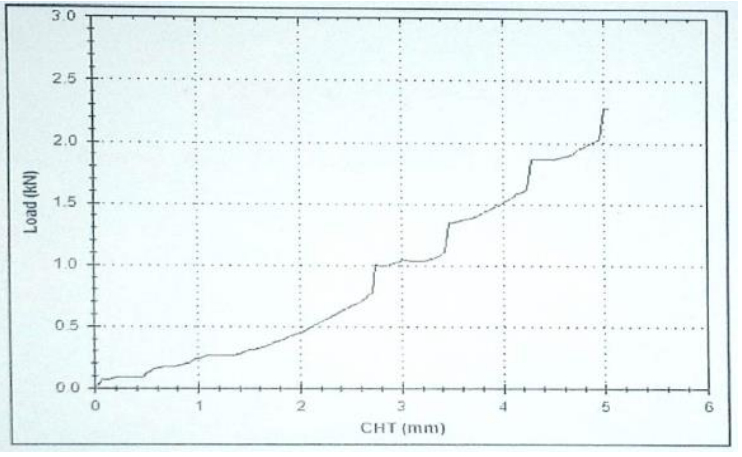

(a) sample 1

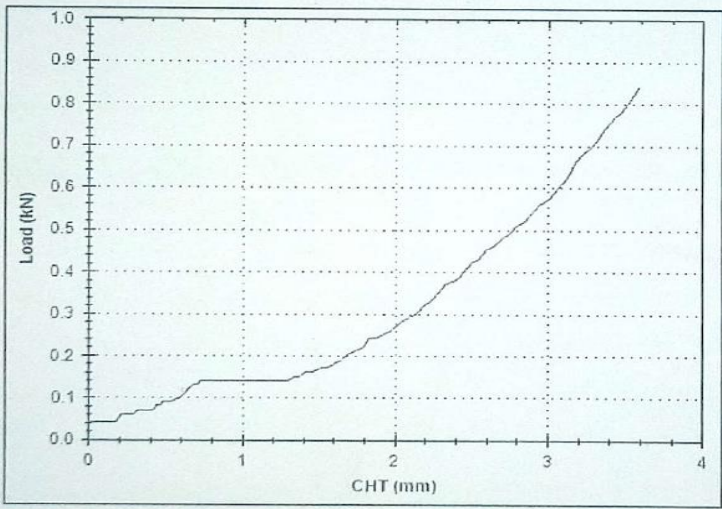

(b) sample 2

Figure 5.1.4: Load v/s displacement diagram for $20 \%$ WAS + 10\% TS

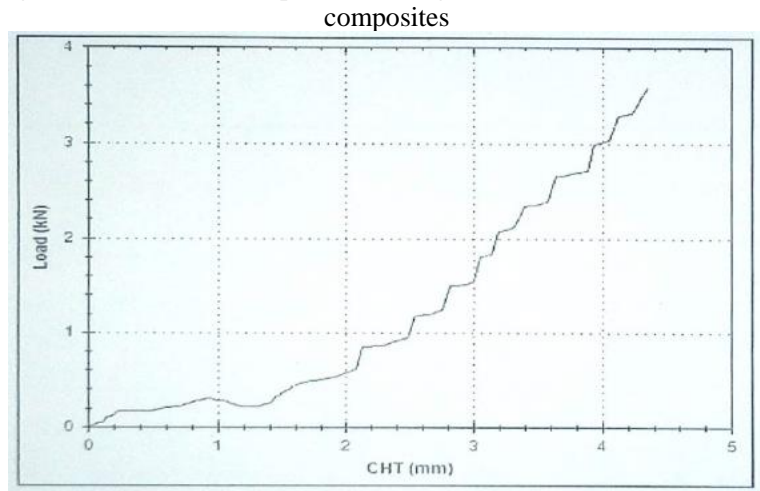

(a) sample 1

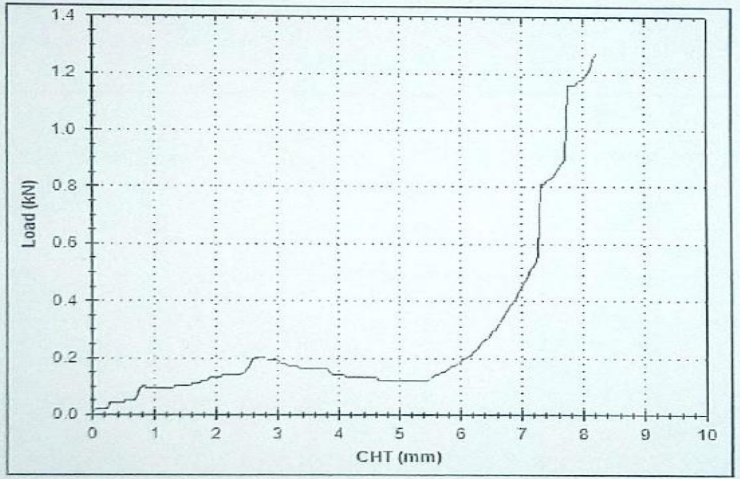

(b) sample 2

Figure 5.1.45 Load v/s displacement diagram for $15 \%$ WAS + 15\% TS composites

\subsection{Compression Test}

Compression test was conducted for the above said specimen categories as per the ASTM standard D3410. 


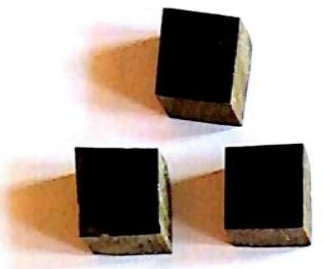

Figure 5.2.1: Compression Test specimens

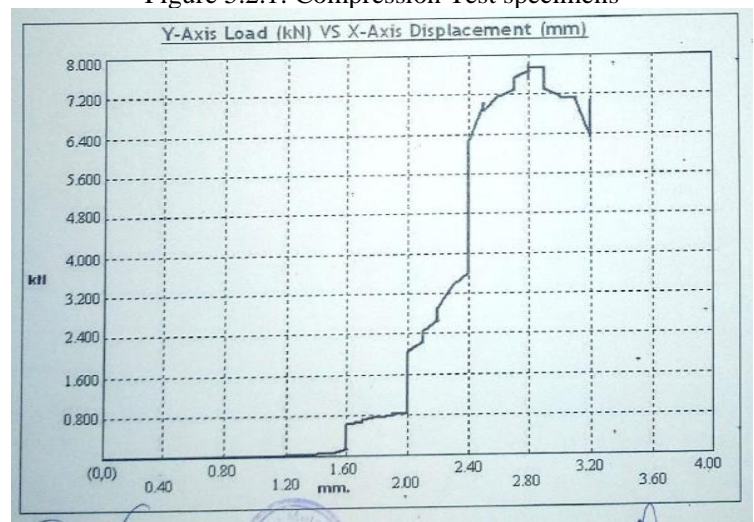

(a) sample 1

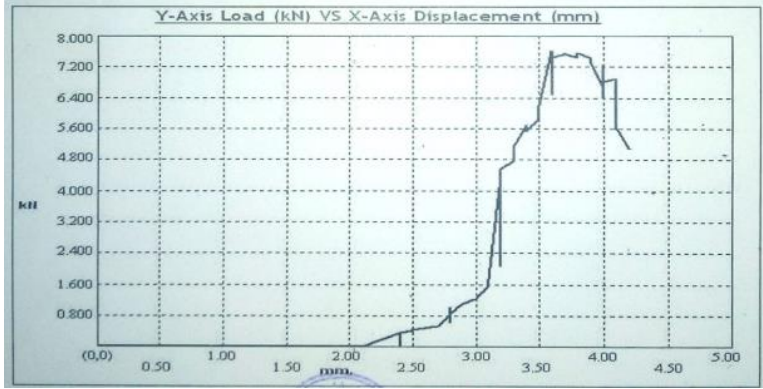

(b) sample 2

Figure 5.2.2: Load v/s displacement diagram for 30\% WAS + 0\% TS composites

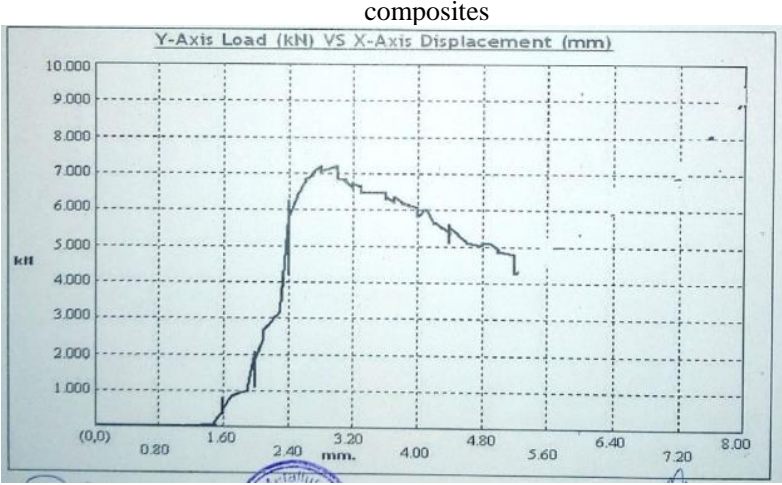

(a) sample 1

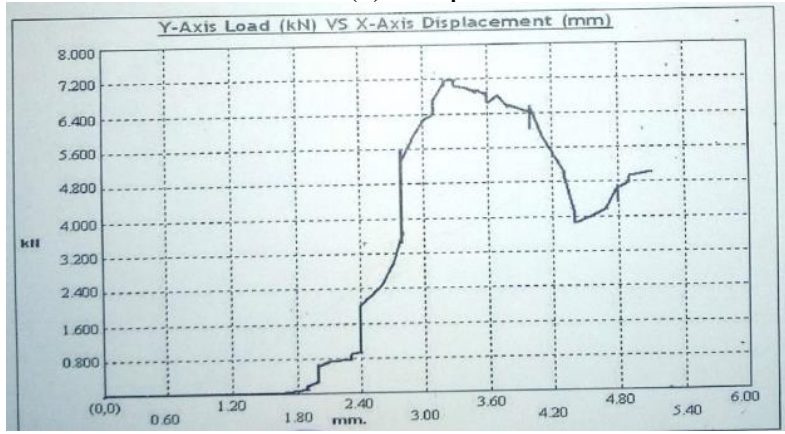

(b) sample 2

Figure 5.2.3: Load v/s displacement diagram for $25 \%$ WAS + 5\% TS composites

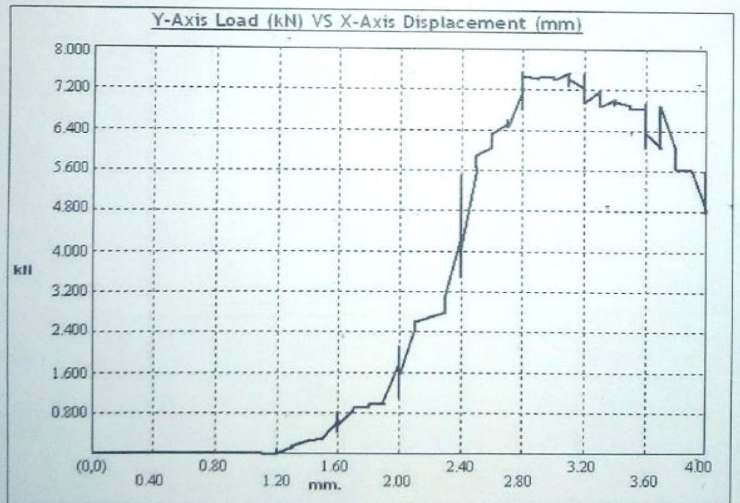

(a) sample 1

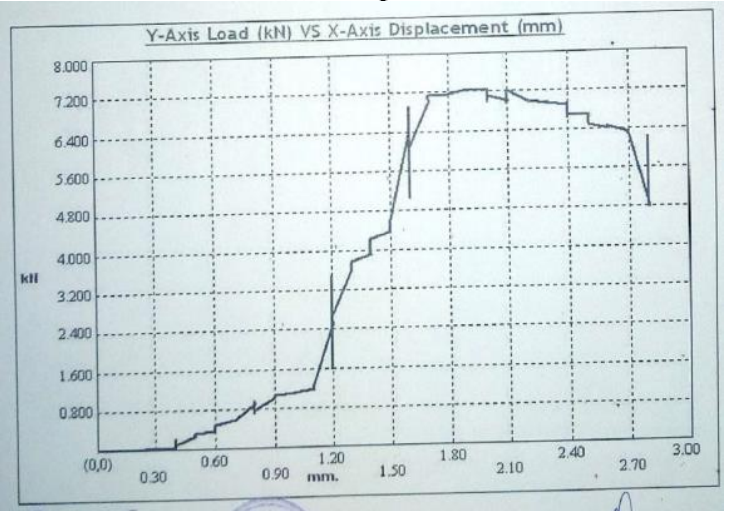

(b) sample 2

Figure 5.2.4: Load v/s displacement diagram for $20 \%$ WAS + $10 \%$ TS composites

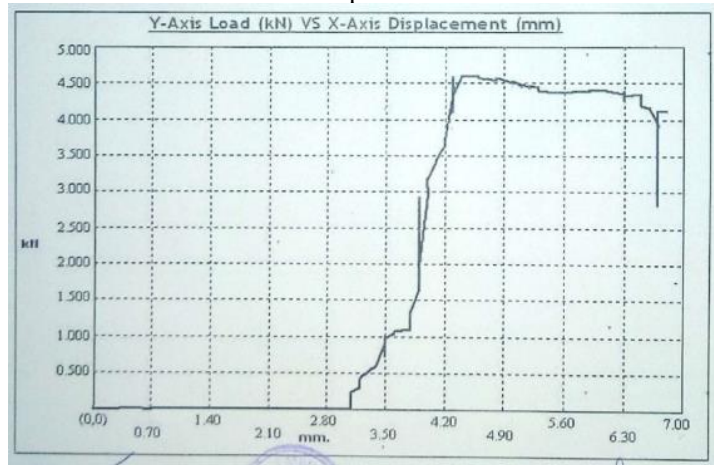

(a) sample 1

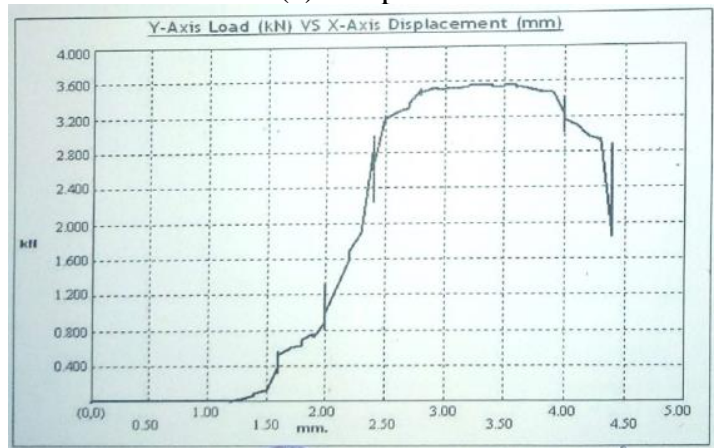

(b) sample 2

Figure 5.2.5: Load v/s displacement diagram for $15 \%$ WAS + 15\% TS composites

\subsection{Impact Test:}

An impact testing machine was used to do the impact test accompanying the specimen standards as per ASTM D 6110 . 


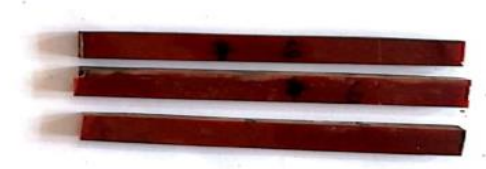

Figure 5.4.1: Impact Test specimen

Table 4: Impact test results for WAP and TS powder composites

\begin{tabular}{|c|c|c|}
\hline Sample Code & $\begin{array}{c}\text { No. of } \\
\text { Readings }\end{array}$ & $\begin{array}{c}\text { Absorbed Energy } \\
\text { (Joules) }\end{array}$ \\
\hline \multirow{2}{*}{$\mathbf{3 0} \%$ WAS + 0\% TS } & 1 & 2 \\
\cline { 2 - 3 } & 2 & 2 \\
\hline \multirow{2}{*}{$\mathbf{2 5} \%$ WAS + 5\% TS } & 1 & 2 \\
\cline { 2 - 3 } & 2 & 2 \\
\hline \multirow{2}{*}{$\mathbf{2 0} \%$ WAS + 10\% TS } & 1 & 2 \\
\cline { 2 - 3 } & 2 & 2 \\
\cline { 2 - 3 } 15\% WAS + 15\% TS & 1 & 2 \\
\hline
\end{tabular}

\section{CONCLUSIONS}

The variation of tensile, bending and harness properties of the tamarind shell and wood apple shell particulate composites was studied. From experimental results, it is found that, composites prepared with $25 \%$ of WAS and 5\% TS powder reinforce epoxy composites exhibited better tensile, compression and flexural properties as compared to $30 \%+0 \%, 20 \%+10 \%$ and $15 \%+15 \%$ combinations.

For impact studies all samples have exhibited the same amount of energy absorption (i. e 2 Joules) for all combinations. This study reveals that, drop in the mechanical properties for the $30 \%$ WAS $+0 \%$ TS composites and slight increment in the mechanical properties for increase in the TS percentage with the WAS.

\section{REFERENCES}

[1] B. A. Acha, N. E. Marcovich, and M. M. Reboredo, Physical and mechanical characterization of jute fabric composites, $\mathrm{J}$. Appl. Polym. Sci. 98, pp. 639-650, 2005.

[2] G. Kalaprasad, K. Joseph, and S. Thomas, Influence of short glass fiber addition on the mechanical properties of sisal reinforced low-density polyethylene composites, J. Compos. Mater. 31, pp. 509-527, 1997

[3] R. K. Misra and N. V. Rachchh, Mechanical performance of coir fiber reinforced polyester composite, J. Adv. Mater. Sci. 1, pp. 19-28, 2011.

[4] M. Sapuan and M. Harimi, Mechanical properties of epoxy/coconut shell filler particle composites, Arab. J. Sci. Eng. 28, pp. 171-181, 2003. 